\title{
Lactobacilli inhibit cervical cancer cell migration in vitro and reduce tumor burden in vivo through upregulation of E-cadherin
}

\author{
XIAOXI LI ${ }^{1}$, HONG WANG $^{2}$, XINGXING DU $^{1}$, WENNA YU ${ }^{1}$, JINGWEN JIANG $^{1}$, \\ YANHONG GENG $^{1}$, XIAOBING GUO $^{1}$, XIUHUA FAN $^{1}$ and CUIQING MA ${ }^{1,3}$ \\ ${ }^{1}$ Department of Gynecology, The Second Hospital of Hebei Medical University, Shijiazhuang, Hebei 050000; \\ ${ }^{2}$ Department of Gynecology, The Fourth Hospital of Shijiazhuang, Shijiazhuang, Hebei 050000; \\ ${ }^{3}$ Department of Immunology, Hebei Medical University, Shijiazhuang, Hebei 050017, P.R. China
}

Received December 9, 2016; Accepted June 23, 2017

DOI: $10.3892 /$ or.2017.5791

\begin{abstract}
The present study was designed to investigate the antitumor effects of Lactobacillus and the potential mechanisms. Cell Counting Kit-8 (CCK-8) assays were carried out to determine suitable doses for investigating the inhibitory effect of lactobacilli on cell migration ability of HeLa and U14 cells in vitro. In addition, western blot assays were performed to investigate the possible mechanisms corresponding to its antitumor effects. Furthermore, a xenograft mouse model was established for investigating the E-cadherin expression in tumor tissues after treatment with lactobacilli. Our results showed that live lactobacilli [multiplicity of infection (MOI) of 1,000:1] significantly possessed inhibitory effects on cell migration ability of cervical cancer cells. Lactobacilli (MOI: 1,000:1) significantly upregulated E-cadherin expressions in HeLa and U14 cells $(\mathrm{p}<0.05)$. On the contrary, our results showed that inactivated lactobacilli could not affect the E-cadherin expression levels in HeLa and U14 cells. Similar to the western blot assay, immunohistochemistry results also indicated that lactobacilli treatment significantly upregulated E-cadherin in tumor tissues $(\mathrm{p}<0.05)$. In conclusion, our results above suggest that lactobacilli have the potential for inhibiting the migratory ability of cervical cancer cell lines, and the possible pharmacological mechanism may be closely related to the upregulation of E-cadherin.
\end{abstract}

Correspondence to: Dr Xiuhua Fan or Dr Cuiqing Ma, Department of Gynecology, The Second Hospital of Hebei Medical University, Shijiazhuang, Hebei 050000, P.R. China

E-mail: xh_fanhi@163.com

E-mail: macq_hbu@163.com

Key words: cervical cancer, Lactobacillus, E-cadherin, cell migration ability

\section{Introduction}

Cervical cancer (CC), one the most common gynecological malignant tumors, is the second cause of cancer-related death in women. In addition, there is no fully effective treatment for CC at present (1). The currently available traditional radiotherapies and chemotherapies for the treatment of $\mathrm{CC}$ have not been able to reduce the rate of mortality, whereas the inevitable side-effects of these mentioned remedies greatly reduce the life quality of $\mathrm{CC}$ patients $(2,3)$. To date, persistent human papilloma virus (HPV) infection is considered as the major pathogen of CC. Furthermore, considering the complexity of antigen and virus subtype diversification, the research for a CC vaccine has increasingly become difficult as well (4). Therefore, it is urgent to discover new treatments to prolong the life of $\mathrm{CC}$ patients and to improve their life quality.

Lactobacillus (lactic acid bacteria), a group of normal bacteria in the woman's vagina, plays a vital role in maintaining normal ecological balance in the vagina (5). Currently, several studies have indicated that CC is closely associated with vaginal micro-ecological balance disorders (6). Previous studies have revealed that a decrease in lactobacillus could lead to the mass propagation of vaginal Gardner or mixed anaerobic bacteria, resulting in production of harmful substances from these two pathogenic bacterial. These harmful substances mentioned above may combine with other carcinogenic factors in the cervix (such as HPV) to accelerate the development of CC (7). Previous studies suggest that epithelial/interstitial transformation (EMT) is not only the basis of the embryonic development process in multicellular organism and organs, but also plays an important role in tumorigenesis, invasion and metastasis, and the occurrence of a variety of chronic diseases $(8,9)$. E-cadherin, one of the most important factors in EMT, promotes cell connection. In addition, it is also demonstrated that downregulation of E-cadherin could be an important factor of CC metastasis $(10,11)$.

The present study aimed to investigate whether or not lactobacillus intervention affects the cell migration of CC cells, and to explore the corresponding pharmacological mechanisms, 
which could be beneficial for identifying a new strategy for future prevention or treatment of $\mathrm{CC}$ in the clinic.

\section{Materials and methods}

Cell lines and bacterial strain. Human carcinoma of the uterine cervix cell lines, HeLa and U14, were supplied by the Department of Immunology, Hebei Medical University (Shijiazhuang, China). Lactobacillus DM8909 (Lactobacillus debrueckii subsp. lactis) was kept in our laboratory and cultured in magnetic resonance spectroscopy (MRS) medium.

Animals. Female BALB/c mice (age, 4-6 weeks old; weight, $20 \pm 2 \mathrm{~g}$ ) were purchased from the Experimental Animal Centre of Hebei Medical University. They were kept at $21 \pm 1^{\circ} \mathrm{C}$ under a 12 -h light/dark cycle with free access to food and water. All animal protocols were approved by the Animal Care and Use Committee of Hebei Medical University.

Chemicals and reagents. Dulbecco's modified Eagle's medium (DMEM), dimethyl sulfoxide (DMSO) and trypsin were purchased from Gibco Co. (Carlsbad, CA, USA). Fetal bovine serum (FBS) was purchased from Hangzhou Sijiqing Biotech (Hangzhou, China). Penicillin and streptomycin were purchased from North China Pharmaceutical Group Corp. (Shijiazhuang, China). Primary antibodies for E-cadherin, vimentin and FOXO4 were purchased from Bioworld Technology, Inc. (St. Louis Park, MN, USA). Primary antibodies for Snail, Twist and $\beta$-catenin were purchased from Abcam Co. (Cambridge, UK). Primary antibody for GAPDH and HRP-conjugated secondary antibody were purchased from SAB Co. (Linhai, China). BSA and PMA kits were purchased from Sigma-Aldrich Co. (Shanghai, China). Cell lysis buffer for western blotting and IP kit and hematoxylin and eosin (H\&E) staining kit were purchased from Beyotime Biotech (Haimen, China). Biotin-labeled secondary antibody and DAB kit were purchased from ZSGB-BIO Co. (Beijing, China). Cell Counting Kit-8 (CCK-8) kit was purchased from Promega Corporation (Madison, WI, USA).

CCK- 8 assay. HeLa and U14 cells were cultured in DMEM containing $10 \%(\mathrm{v} / \mathrm{v}) \mathrm{FBS}, 100 \mathrm{U} / \mathrm{ml}$ streptomycin and $100 \mathrm{U} / \mathrm{ml}$ penicillin at $37^{\circ} \mathrm{C}$ with $5 \% \mathrm{CO}_{2}$. Cells $\left(5 \times 10^{3} / 100 \mu \mathrm{l}\right)$ were seeded in 96 -well plates and cultured for $8 \mathrm{~h}$ at $37^{\circ} \mathrm{C}$. Subsequently, lactobacilli at different MOIs (10:1, 100:1 and 1,000:1) were added to the well and incubated for 24,48 and $72 \mathrm{~h}$, respectively. Then, the plates were carefully washed with culture medium to remove the lactobacilli and subsequently $10 \mu 1$ CCK-8 reagent with culture medium was added to each well, and the cells were cultured for another $2.5 \mathrm{~h}$ at $37^{\circ} \mathrm{C}$ with $5 \% \mathrm{CO}_{2}$. Optical density (OD) values were determined at $450 \mathrm{~nm}$ by an HT2 microplate reader (Thermo Fisher Scientific Co., Carlsbad, CA, USA).

Wound healing assay. After the CCK-8 determination, a wound healing assay was carried out according to the methods previously reported with minor modifications (12). Briefly, HeLa cells were cultured in 6-well plates for $24 \mathrm{~h}$, and then a $10 \mu 1$ sterile pipette was applied to scratch the cell layer to form a linear wound. Then, the cells were washed 3 times with cold phosphate-buffered saline (PBS) buffer, and incubated with lactobacilli for another 24, 48 and $72 \mathrm{~h}$, respectively. After being washed with PBS buffer 3 times, migration of the cells in each group was measured under an inverted microscope (LH50A; Olympus, Tokyo, Japan).

Western blot assay. E-cadherin expression in the CC cells and $\mathrm{CC}$ tumor tissues was examined by western blotting. Briefly, total proteins of CC cells or tissues were harvested after treatment with cell lysis buffer for western blotting and IP kit. Then, the protein contents were determined and equal amounts of protein $(40 \mu \mathrm{g})$ were separated using $10 \%$ sodium dodecyl sulfate-polyacrylamide gel electrophoresis (SDS-PAGE), and subseqently blotted on polyvinylidene difluoride (PVDF) membranes. Then, the protein bands were probed with primary antibodies for the corresponding detecting proteins, respectively and subsequently with goat anti-rabbit horseradish peroxidase (HRP). Finally, the protein bands were visualized and detected by a chemiluminescence method. In addition, GAPDH was used as the internal reference to normalize the protein loading, and the target protein expression levels were expressed as a relative value to that of GAPDH.

Xenograft assay in vivo. The effects of lactobacilli were determined using an xenograft animal model on female BALB/c mice according to a previous study (13). Briefly, a total of 25 mice were randomly divided into 5 groups $(n=5)$ : i) PBS-treated mice; ii and iii) inactivated lactobacilli-treated mice ( 2.25 and $5.0 \times 10^{6} / \mathrm{mice} /$ day); iv and v) lactobacilli-treated mice (2.25 and 5.0x10\%/mice/day). U14 cells $\left(2.0 \times 10^{6} / 0.2 \mathrm{ml} /\right.$ mouse) were subcutaneously injected into the right flank of each mouse. After tumors grew to $\sim 2-3 \mathrm{~mm}$ in diameter, the mice were intraperitoneally injected (i.p.) with PBS, inactivated lactobacilli (2.25 and 5.0x $10^{6} / \mathrm{mice} /$ day) or lactobacilli (2.25 and $\left.5.0 \times 10^{6} / \mathrm{mice} / \mathrm{day}\right)$ for a continuous 20 days. Tumor sizes were measured every 4 days. Tumor volume $(V)$ was calculated using a reported formula (14): $\mathrm{V}=\left(\right.$ width $^{2} \mathrm{x}$ length $) / 2$.

All mice were sacrificed after 21 days of treatment, and the tumors were separated and weighed. Then, the tumor tissues were collected for the following western blot and immunohistochemistry assays.

Immunohistochemistry assay. Tumor tissue was collected and fixed in $10 \%$ formalin and then tissue sections were prepared according to normal and standard protocols. Then, tissue sections were stained with a primary antibody for E-cadherin and subsequently stained with biotin-labeled secondary antibody. Furthermore, quantitative analysis of the results was performed using an image analysis system (Motic Med 6.0; Motic China Group Co., Ltd., Tokyo, Japan).

Statistical analysis. Data are presented as means \pm SD. Differences between groups were evaluated using multiple comparisons of the data as performed by ANOVA with Dunnett's test. P-values $<0.05$ were considered significant.

\section{Results}

Lactobacilli at MOIs of 10:1, 100:1 and 1,000:1 had no effect on the proliferation of $C C$ cell lines. The cytotoxic 

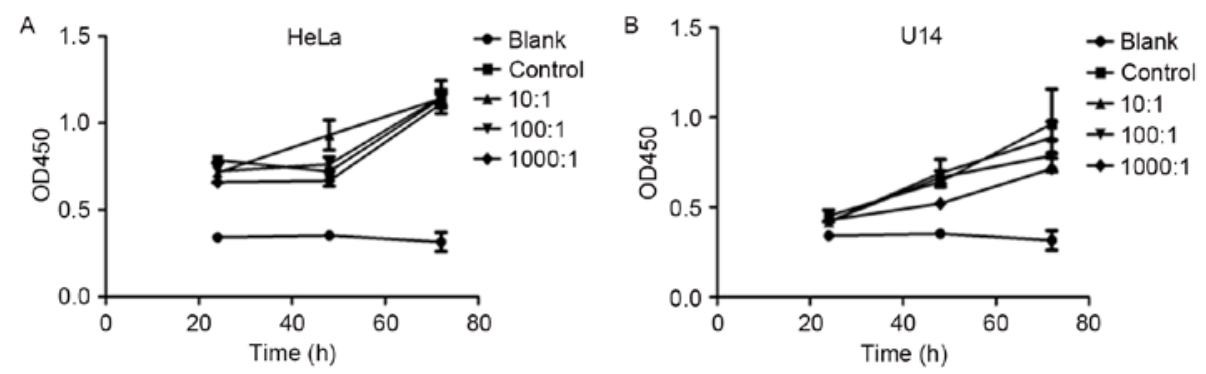

Figure 1. Effects of lactobacillus on the proliferation of cervical cancer (CC) cell lines. Cells were incubated with lactobacillus (MOI: 10:1, 100:1, 1,000:1) for 24, 48 and $72 \mathrm{~h}$, and then CCK-8 assays were carried out to determine the effects of lactobacillus on the proliferation of CC cell lines: (A) HeLa and (B) U14.
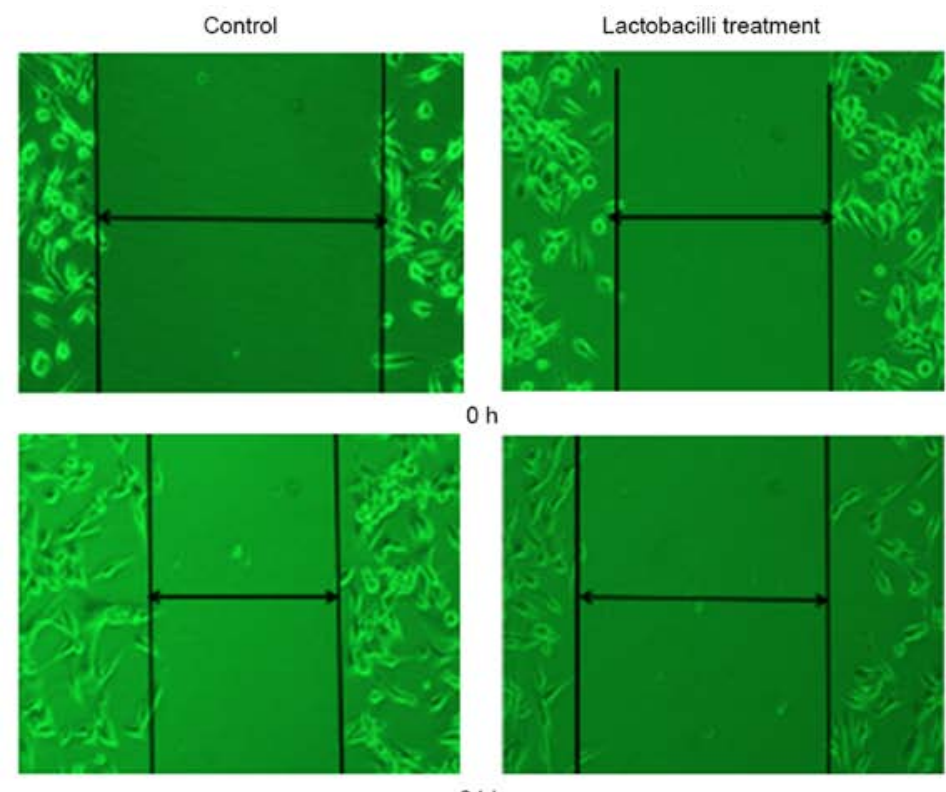

$24 \mathrm{~h}$
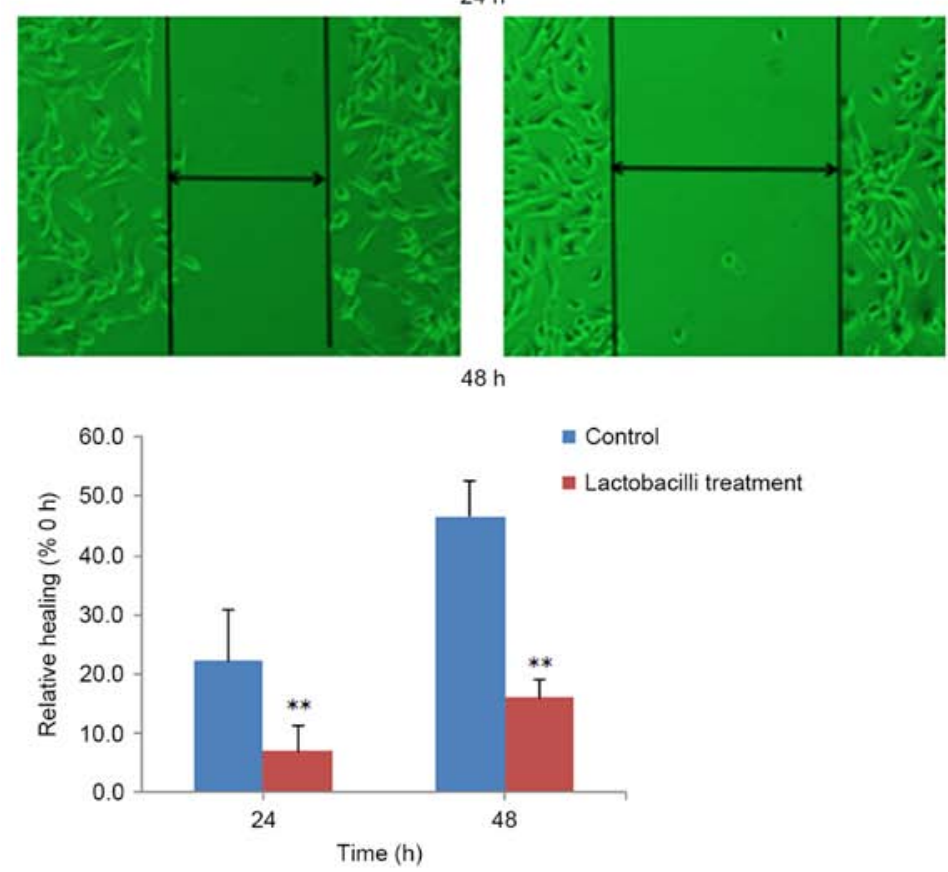

Figure 2. Results of the wound healing assay in the HeLa cell line. Cells were incubated with lactobacilli (MOI: 1,000:1) for 24 and 48 h, and then the migration distances were determined. Data are represented as mean \pm SD $(n=3),{ }^{* *} \mathrm{p}<0.01$, compared to the control.

effects of lactobacilli against $\mathrm{CC}$ cell lines were determined using CCK-8 assays. As shown in Fig. 1, after incubation with lactobacilli under the multiplicity of infection (MOI) of 10:1, 100:1 and 1,000:1 for 2, 48 and $72 \mathrm{~h}$, the cell proliferation of 

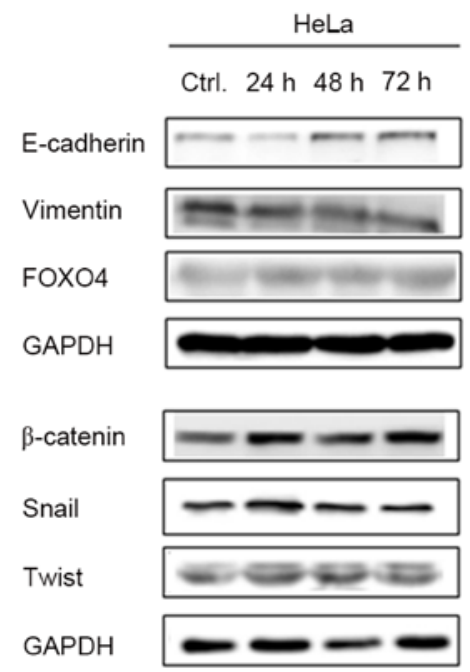

HeLa Snail

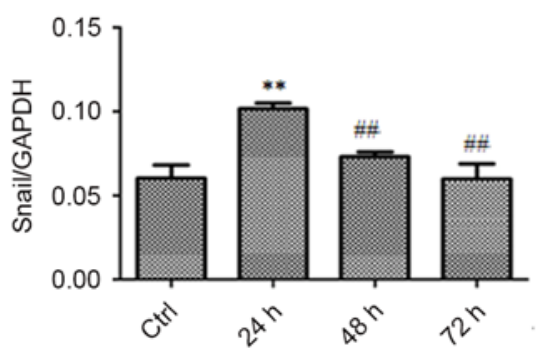

U14 E-cadherin

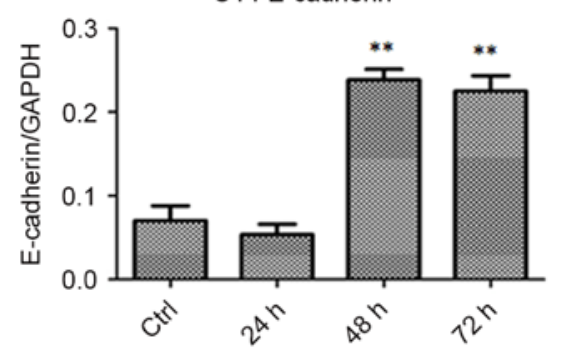

Ctrl. 24 h 48 h 72 h

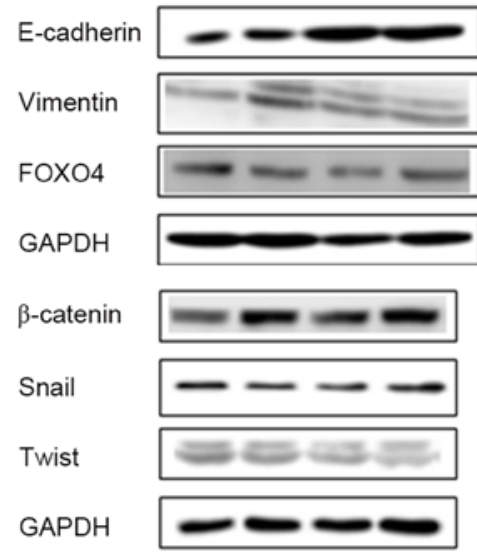

HeLa E-cadherin

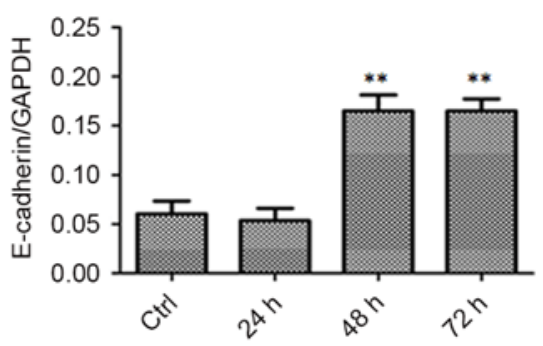

Figure 3. Effects of lactobacilli on E-cadherin, vimentin, FOXO4, Twist, $\beta$-catenin and Snail expression levels in cervical cancer (CC) cell lines. Ctrl, control. GAPDH was used as the internal reference to normalize the protein loading, and the target protein expression levels are expressed as a relative value to that of GAPDH. Data are represented as mean $\pm \mathrm{SD}(\mathrm{n}=4) ;{ }^{* *} \mathrm{p}<0.01$, compared to the $\mathrm{Ctrl} ;{ }^{\# \#} \mathrm{p}<0.01$, compared to cells at $24 \mathrm{~h}$.

both the HeLa and U14 cell lines was not significantly affected $(p>0.05, p>0.05)$. These results showed that the MOIs selected did not affect the cell viability of the $\mathrm{CC}$ cell lines, and were suitable for further investigation of the inhibitory effect of lactobacilli on cell migration.

Lactobacilli significantly inhibit cell migration of HeLa cells. After selecting suitable MOIs of lactobacilli, we further investigated the effects of lactobacilli on the migration of HeLa cells using wound healing assay. From the results shown in Fig. 2, we concluded that lactobacilli at the MOI of 1,000:1 obvious inhibited the migration of the HeLa cells after incubation for $24 \mathrm{~h}(\mathrm{p}<0.01)$ and $48 \mathrm{~h}(\mathrm{p}<0.01)$.

Lactobacilli upregulate E-cadherin and Snail expression in the CC cell lines. Furthermore, we explored the potential pharmacological mechanisms of lactobacilli by western blot assays. As shown in Fig. 3, in both the HeLa and U14 cell lines, treatment with lactobacilli significantly upregulated the expression of E-cadherin after $48(\mathrm{p}<0.01)$ and $72 \mathrm{~h}(\mathrm{p}<0.01)$ of incubation, compared with the control (Ctrl) group. In addition, Snail expession in HeLa cells was also upregulated at $24 \mathrm{~h}(\mathrm{p}<0.01)$ after lactobacillus treatment, compared with that noted in the Ctrl group, and sharply decreased after $48 \mathrm{~h}$, compared to the $24 \mathrm{~h}$ cells.

Lactobacilli upregulate E-cadherin via its secreted constituents. As shown in Fig. 4, active lactobacilli significantly upregulated the E-cadherin protein levels in the HeLa cells after $48(\mathrm{p}<0.01)$ and $72 \mathrm{~h}(\mathrm{p}<0.01)$ of culture, compared to the level in the Ctrl cells. Similar to HeLa cells, treatment with lactobacilli obviously increased the E-cadherin expressions after $24(\mathrm{p}<0.01), 48(\mathrm{p}<0.01)$ and $72 \mathrm{~h}(\mathrm{p}<0.01)$ of culture in the U14 cells, compared with that in the Ctrl cells. On the contrary, inactivated lactobacilli could not affect the E-cadherin expression in both HeLa and U14 cell lines, 
A

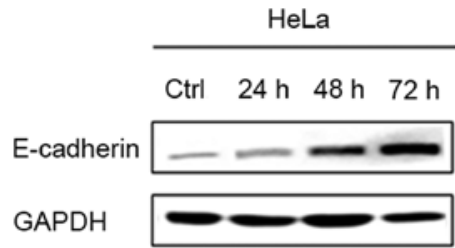

HeLa E-cadherin

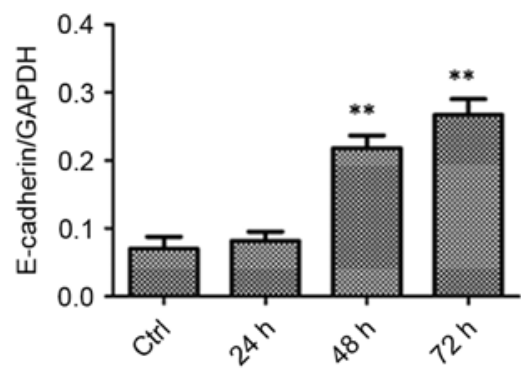

B

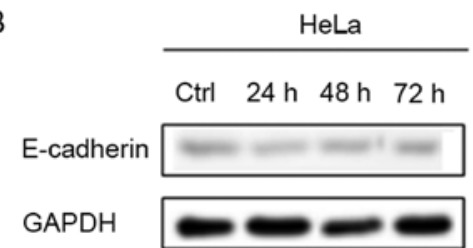

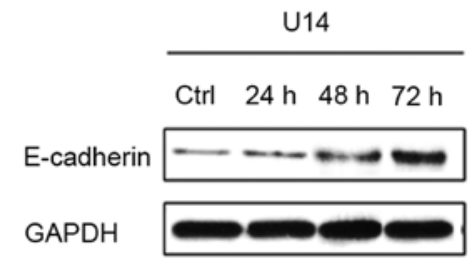

U14 E-cadherin
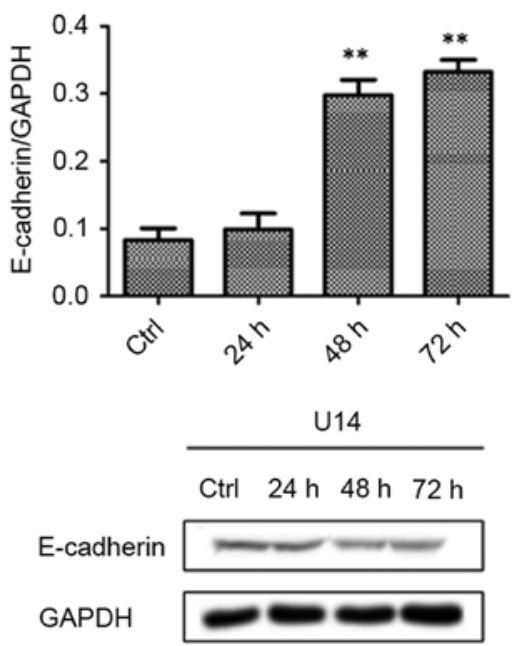

Figure 4. Effects of lactobacilli on E-cadherin expression in cervical cancer (CC) cell lines. Ctrl, control. (A) Effects of lactobacilli on E-cadherin expression. (B) Effects of inactivated lactobacilli on E-cadherin expression. GAPDH was used as the internal reference to normalize the protein loading, and the target protein expression levels are expressed as a relative value to that of GAPDH. Data are represented as mean $\pm \mathrm{SD}(\mathrm{n}=4) ;{ }^{* *} \mathrm{p}<0.01$, compared to Ctrl.
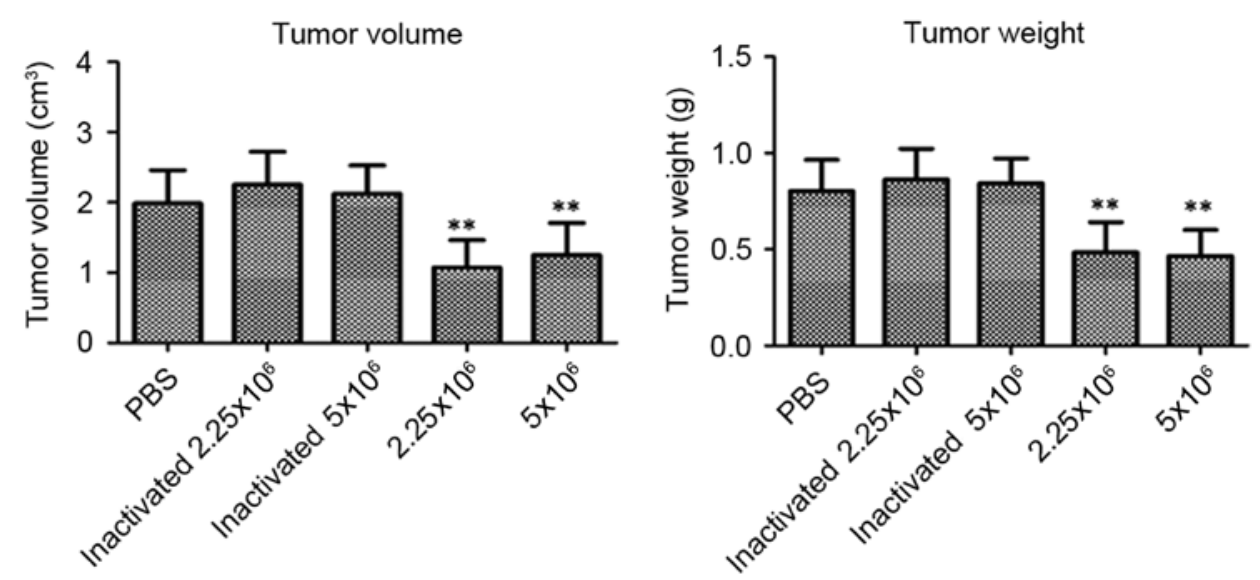

Figure 5. Effects of lactobacilli on tumor weight and volume in the U14 tumor-burdened mice at day 21. Data are represented as mean $\pm \mathrm{SD}(\mathrm{n}=5) ;{ }^{* *} \mathrm{p}<0.01$, compared to the PBS mice.

compared with levels in the Ctrl cells ( $\mathrm{p}>0.05)$. These results as mentioned above indicate that live lactobacilli upregulated the E-cadherin expression in CC cells instead of inactivated lactobacilli; therefore, the potential mechanisms may be related to various secreted constituents of live lactobacilli.

Lactobacilli decrease tumor weight and volume in the tumorburdened mice. From the results shown in Fig. 5, lactobacillus treatments $\left(2.25\right.$ and $5.0 \times 10^{6} /$ mice $)$ significantly decreased the volume $(\mathrm{p}<0.01, \mathrm{p}<0.01)$ and weight $(\mathrm{p}<0.01, \mathrm{p}<0.01)$ of the tumors in the mice, compared with the PBS-treated mice. In addition, the inactivated lactobacilli did not affect the tumor growth in the U14 tumor-burdened mice ( $\mathrm{p}>0.05)$.
Lactobacilli upregulate E-cadherin in the tumor-burdened mice. Furthermore, we determined the protein expression levels of E-cadherin, vimentin, $\beta$-catenin, Snail and Twist in the tumor tissues of the tumor-burdened mice at 21 days by western blot assays. As shown in Fig. 6, no obvious difference was observed between the PBS-treated mice and the inactivated/activated lactobacillus-treated mice for the proteins of vimentin $(p>0.05), \beta$-catenin $(p>0.05)$, Snail $(p>0.05)$ and Twist ( $p>0.05$ ). Importantly and notably, compared with the PBS-treated mice, the lactobacilli significantly upregulated the E-cadherin expression in the tumor tissues at the doses of $2.25 \times 10^{6} /$ mice $(p<0.01)$ and $5.0 \times 10^{6} /$ mice $(p<0.01)$. On the contrary, the inactivated lactobacilli did not affect the 

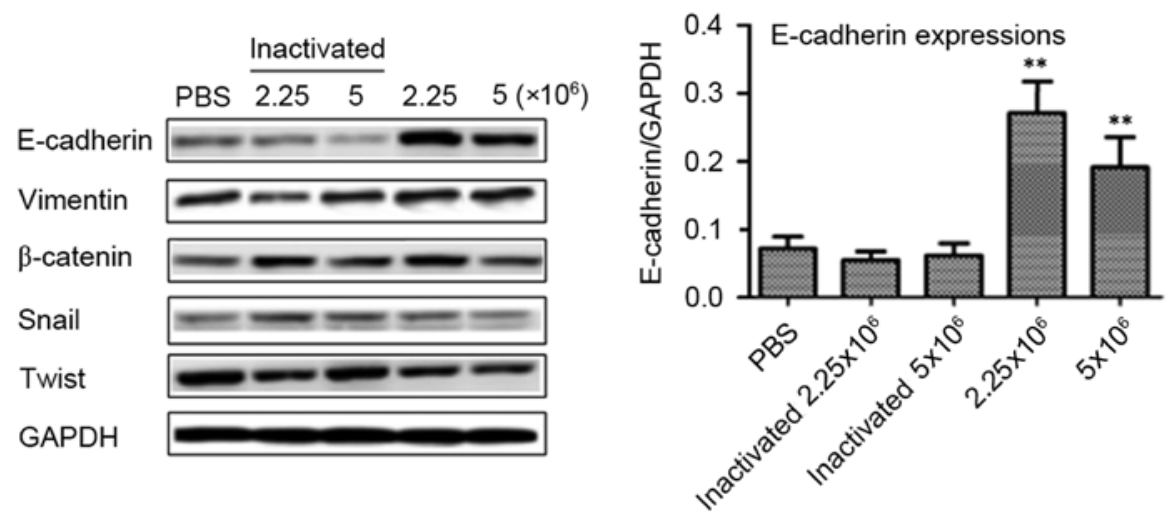

Figure 6. Effects of lactobacilli on E-cadherin, vimentin, $\beta$-catenin, Snail and Twist in tumor-burdened mice at day 21. GAPDH was used as the internal reference to normalize the protein loading, and the target protein expression levels are expressed as a relative value to that of GAPDH. Data are represented as mean $\pm \mathrm{SD}(\mathrm{n}=5) ;{ }^{* *} \mathrm{p}<0.01$, compared to PBS mice.

A

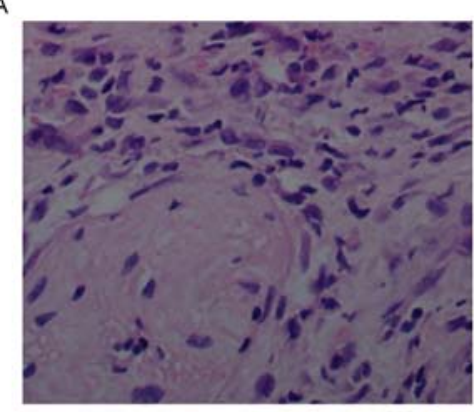

C
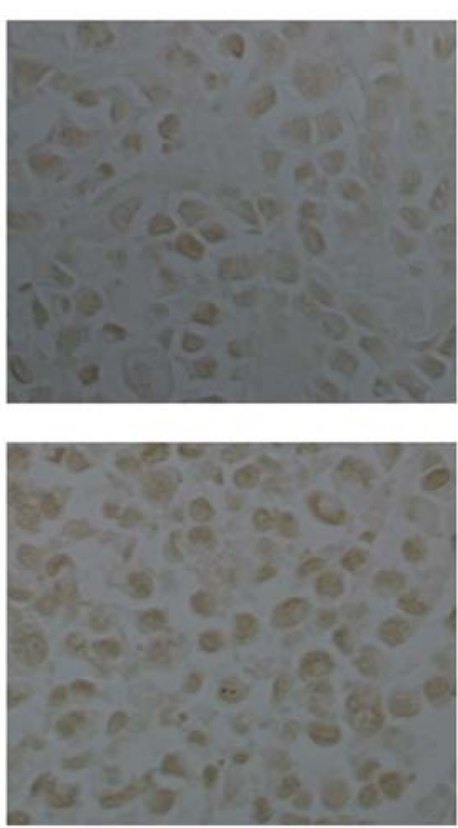
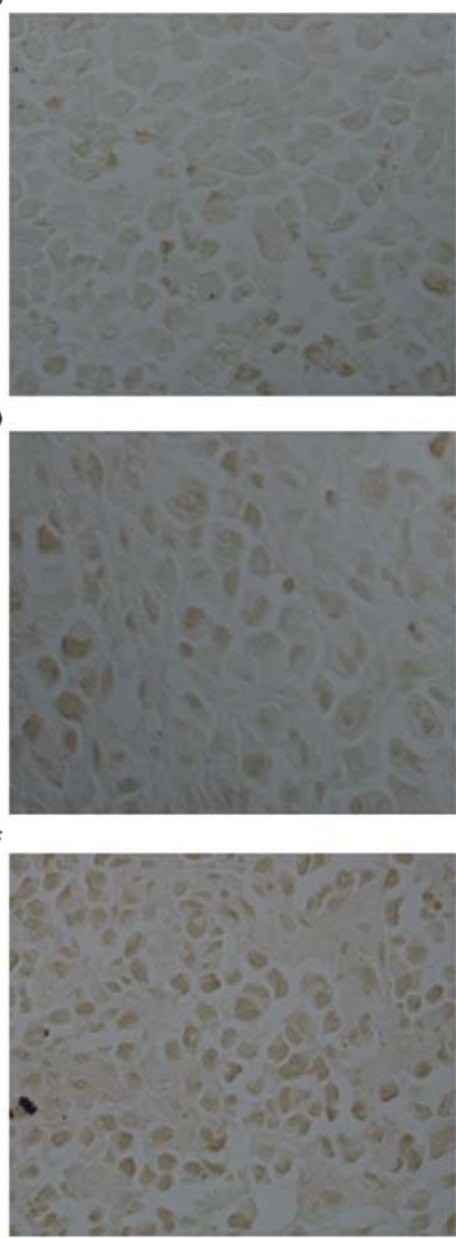

Figure 7. E-cadherin expression in U14 tumor tissues at day 21. (A) H\&E staining of the tumor tissues. (B-F) E-cadherin antibody staining of tumor tissues from the PBS-treated mice, inactivated lactobacilli-treated mice (2.25 and 5.0x10 $/ \mathrm{mice})$ and lactobacillus-treated mice $\left(2.25\right.$ and $\left.5.0 \times 10^{6} / \mathrm{mice}\right)$, respectively (yellow-brown represents positive E-cadherin expression; magnification, $\mathrm{x} 400$ ).

E-cadherin expression compared with that in the PBS-treated mice $(\mathrm{p}>0.05)$.

E-cadherin expression in U14 tumor tissues. In addition, we further determined the protein expression level of E-cadherin in tumor tissues using immunohistochemical assay with E-cadherin antibody straining. As shown in Fig. 7 and Table I, in the tumor tissues of the PBS-treated mice, the expression level of E-cadherin was low (Fig. 7B; Table I). For the inactivated lactobacillus-treated mice (2.25 and 5.0x $\left.10^{6} / \mathrm{mice}\right)$, the E-cadherin expression levels were still low (Fig. 7C and D; Table I), and did not show obvious differences compared to the PBS-treated mice $(p>0.05, p>0.05)$. Notably, the lactobacillus treatments $\left(2.25\right.$ and $\left.5.0 \times 10^{6} / \mathrm{mice}\right)$ significantly upregulated 
Table I. E-cadherin expression in U14 tumor tissues.

\begin{tabular}{|c|c|c|c|c|}
\hline \multirow[b]{2}{*}{ PBS } & \multicolumn{2}{|c|}{ Inactivated lactobacilli } & \multicolumn{2}{|c|}{ Lactobacilli } \\
\hline & $2.25 \times 10^{6} /$ mice & $5 \times 10^{6} /$ mice & $2.25 \times 10^{6} / \mathrm{mice}$ & $5 \times 10^{6} /$ mice \\
\hline $0.137 \pm 0.004$ & $0.140 \pm 0.003$ & $0.138 \pm 0.005$ & $0.477 \pm 0.006^{\mathrm{a}}$ & $0.467 \pm 0.003^{\mathrm{a}}$ \\
\hline
\end{tabular}

Data are represented as mean $\pm \mathrm{SD}(\mathrm{n}=5),{ }^{\mathrm{a}} \mathrm{p}<0.01$, compared to PBS-treated mice. PBS, phosphate-buffered saline.

the protein expression level of E-cadherin in the tumor tissues $(\mathrm{p}<0.05, \mathrm{p}<0.05)$, compared with that in the PBS-treated mice (Fig. 7E and F; Table I).

\section{Discussion}

Previous research has demonstrated that tumor cell invasion and migration to the extracellular matrix (ECM) is the crucial step in tumor metastasis (15). In the present study, the wound healing assay results indicated that lactobacilli could significantly inhibit the migration of cervical cancer (CC) cells in vitro. In addition, CCK-8 assay results demonstrated that the inhibitory effects of lactobacilli on the migration of CC cells are not due to its cytotoxicity. These results as mentioned above suggest that lactobacilli have potential inhibitory effects on CC cell migration ability. Epithelialmesenchymal transition (EMT) plays an important role in the development, invasion and metastasis of tumors, and invasion and metastasis are two crucial hallmarks of malignancy which commonly results in the loss of E-cadherin. In addition, previous studies have revealed that E-cadherin loss is the most important event in the development of EMT $(10,11)$. E-cadherin, a 12-kDa calcium-dependent membrane glycoprotein, possesses important physiological activities regarding the maintenance of cell-cell adhesion, epithelial tissue polarity and structural integrity (15-17). Increasing evidence has demonstrated that levels of E-cadherin are commonly downregulated in various human malignancies, including lung and skin cancer, oral squamous carcinoma, as well as CC. Thus, low E-cadherin expression has been considered as an indicator of the poor prognosis of tumors $(18,19)$. Our present research showed that lactobacilli notably upregulated the E-cadherin expression in CC tumor cells in vitro and in vivo, indicating that this effect may be a key factor attributed to its inhibitory effects on $\mathrm{CC}$ cell migration ability.

The Wnt $/ \beta$-catenin signaling pathway also plays an important role in the development of cancers, and previous studies have indicated that $\beta$-catenin takes part in the process of ETM in the invasion of colorectal cancer (20-22). Previous research indicates that overexpression of WIF1 (an inhibitor of Wnt) in PC3 cells effectively inhibited the expression of transcription factors of Slug and Twist, leading to upregulation of E-cadherin whereas loss of vimentin is a hallmark of mesenchymal cells $(22,23)$. Our present investigation revealed that lactobacilli induced upregulation of E-cadherin, but showed no effect on expression of vimentin, suggesting that the inhibitory effects of lactobacilli on CC cell migration may possess no relation with vimentin. Furthermore, Snail, a DNA-binding protein, recognizes and binds to the E-box sequence in the promoter of the E-cadherin gene, subsequently resulting in low expression of E-cadherin, leading to the development of EMT. Thus, Snail could promote the invasive and metastatic abilities of tumors, such as gastric cancer $(24,25)$. However, there is no evidence for the Snail expression in CC. In our present results, we found that after culture with lactobacilli for $24 \mathrm{~h}$, the Snail expression in HeLa cells was upregulated; however this effect was not detected in $\mathrm{U} 14$ cells in vitro and tumor tissues in vivo. Thus, the inhibitory effects of lactobacilli may be not related to Snail. Twist 1 binds to $\beta$-catenin, leading to promotion of the development of tumors. In addition, Yang et al reported that Twist 1 inhibits the expression of E-cadherin in human mammary epithelial cells $(26,27)$. FOXO transcription factors play important roles in the proliferation, differentiation and apoptosis of cells. Yang et al revealed that FOXO4 inhibited tumor cell proliferation. Tang et al indicated that FOXO4 upregulated Bcl-6 which could bind to the promoter of Bcl-2, leading to the downregulation of $\mathrm{Bcl}-2(28,29)$. However, our present results did not provide an obvious evidence for demonstrating that the upregulation of E-cadherin by lactobacilli is related to the regulation of Twist 1 and FOXO4. In addition, we also investigated whether or not the inhibitory effects of lactobacilli on the migration of $\mathrm{CC}$ cells were due to the surface proteins of lactobacilli. Our results showed that inactivated lactobacilli had no obvious effects on tumor growth and E-cadherin expression. Thus, we deduced that the active components of lactobacilli may be related to various secreted constituents of live lactobacilli.

In conclusion, our results indicate that live lactobacilli have potential activities for inhibiting the migration of CC cells, and the possible pharmacological mechanism may be closely related to the upregulation of E-cadherin.

\section{Acknowledgements}

The present study was supported by funding from the Hebei Provincial Health and Family Planning Commission (no. 20150630).

\section{References}

1. Vaccarella S, Franceschi S, Zaridze D, Poljak M, Veerus P, Plummer $M$ and Bray F: Preventable fractions of cervical cancer via effective screening in six Baltic, central, and eastern European countries 2017-40: A population-based study. Lancet Oncol 17: 1445-1452, 2016. 
2. Lee SJ, Yang A, Wu TC and Hung CF: Immunotherapy for human papillomavirus-associated disease and cervical cancer: Review of clinical and translational research. J Gynecol Oncol 27: e51, 2016.

3. Muñoz N, Bosch FX, de Sanjosé S, Herrero R, Castellsagué X, Shah KV, Snijders PJ and Meijer CJ; International Agency for Research on Cancer Multicenter Cervical Cancer Study Group: Epidemiologic classification of human papillomavirus types associated with cervical cancer. N Engl J Med 348: 518-527, 2003.

4. Dochez C, Bogers JJ, Verhelst R and Rees H: HPV vaccines to prevent cervical cancer and genital warts: An update. Vaccine 32: $1595-1601,2014$.

5. Xiao BB and Liao QP: Research progress of vaginal microecology. J Int Obstet Gynecol 38: 479-482, 2011.

6. Lu FG, Hu JZ, Wu CR, Hu ZG and Zhao WN: Study of biological antagonism on lactobacilli in human vaginae. Pract Prev Med 8: 19-20, 2001.

7. Voravuthikunchai SP, Bilasoi S and Supamala O: Antagonistic activity against pathogenic bacteria by human vaginal lactobacilli. Anaerobe 12: 221-226, 2006.

8. Mlcochova H, Machackova T, Rabien A, Radova L, Fabian P, Iliev R, Slaba K, Poprach A, Kilic E, Stanik M, et al: Epithelialmesenchymal transition-associated microRNA/mRNA signature is linked to metastasis and prognosis in clear-cell renal cell carcinoma. Sci Rep 6: 31852, 2016.

9. Zhang Z, Chen H, Xu C, Song L, Huang L, Lai Y, Wang Y, Chen H, Gu D, Ren L, et al: Curcumin inhibits tumor epithelialmesenchymal transition by downregulating the Wnt signaling pathway and upregulating NKD2 expression in colon cancer cells. Oncol Rep 35: 2615-2623, 2016.

10. Braga V: Spatial integration of E-cadherin adhesion, signalling and the epithelial cytoskeleton. Curr Opin Cell Biol 42: 138-145, 2016.

11. Carvalho S, Oliveira T, Bartels MF, Miyoshi E, Pierce M, Taniguchi N, Carneiro F, Seruca R, Reis CA, Strahl S, et al: $O$-mannosylation and $N$-glycosylation: Two coordinated mechanisms regulating the tumour suppressor functions of E-cadherin in cancer. Oncotarget 7: 65231-65246, 2016.

12. Yang XK, Yang YD and Tang SQ: Inhibitory effect of polysaccharides from Scutellaria barbata D. Don on invasion and metastasis of 95-D cells lines via regulation of C-MET and E-CAD expressions. Trop J Pharm Res 12: 517-522, 2013.

13. Peng W, Wu JG, Jiang YB, Liu YJ, Sun T, Wu N and Wu CJ: Antitumor activity of 4-O-(2"-O-acetyl- $6^{\prime \prime}-\mathrm{O}-p$-coumaroyl- $\beta$ D-glucopyranosyl)- $p$-coumaric acid against lung cancers via mitochondrial-mediated apoptosis. Chem Biol Interact 233: 8-13, 2015.

14. Zhou T, Li G, Cao B, Liu L, Cheng Q, Kong H, Shan C, Huang X, Chen J and Gao N: Downregulation of Mcl-1 through inhibition of translation contributes to benzyl isothiocyanate-induced cell cycle arrest and apoptosis in human leukemia cells. Cell Death Dis 4: e515, 2013.

15. Kalluri R and Weinberg RA: The basics of epithelial-mesenchymal transition. J Clin Invest 119: 1420-1428, 2009.

16. Martínez A, Spencer ML, Borlando J, Flores M and Rojas IG: E-cadherin and c-Met expression in actinic cheilits and lip squamous cell carcinoma. Rehabil Oral 4: 122-125, 2011.
17. Yao Z and Shulan Z: Inhibition effect of Guizhi-Fuling-decoction on the invasion of human cervical cancer. J Ethnopharmacol 120: 25-35, 2008.

18. Dohadwala M, Yang SC, Luo J, Sharma S, Batra RK, Huang M, Lin Y, Goodglick L, Krysan K, Fishbein MC, et al: Cyclooxygenase-2-dependent regulation of E-cadherin: Prostaglandin $\mathrm{E}_{2}$ induces transcriptional repressors ZEB1 and snail in non-small cell lung cancer. Cancer Res 66: 5338-5345, 2006.

19. Valizadeh A, Karayiannakis AJ, el-Hariry I, Kmiot W and Pignatelli M: Expression of E-cadherin-associated molecules (alpha-, beta-, and gamma-catenins and p120) in colorectal polyps. Am J Pathol 150: 1977-1984, 1997.

20. Hlubek F, Spaderna S, Schmalhofer O, Jung A, Kirchner T and Brabletz T: Wnt/FZD signaling and colorectal cancer morphogenesis. Front Biosci 12: 458-470, 2007.

21. Rattner A, Hsieh JC, Smallwood PM, Gilbert DJ, Copeland NG, Jenkins NA and Nathans J: A family of secreted proteins contains homology to the cysteine-rich ligand-binding domain of frizzled receptors. Proc Natl Acad Sci USA 94: 2859-2863, 1997.

22. Wissmann C, Wild PJ, Kaiser S, Roepcke S, Stoehr R, Woenckhaus M, Kristiansen G, Hsieh JC, Hofstaedter F, Hartmann A, et al: WIF1, a component of the Wnt pathway, is down-regulated in prostate, breast, lung, and bladder cancer. J Pathol 201: 204-212, 2003.

23. Yee DS, Tang Y, Li X, Liu Z, Guo Y, Ghaffar S, McQueen P, Atreya D, Xie J, Simoneau AR, et al: The Wnt inhibitory factor 1 restoration in prostate cancer cells was associated with reduced tumor growth, decreased capacity of cell migration and invasion and a reversal of epithelial to mesenchymal transition. Mol Cancer 9: 162, 2010.

24. Galván JA, González MV, Crespo G, Folgueras MV and Astudillo A: Snail nuclear expression parallels higher malignancy potential in neuroendocrine lung tumors. Lung Cancer 69: 289-295, 2010.

25. Lee SH, Kim JH and Lee YS: M1958 regulation of GLI1 and snail in Helicobacter pylori infected gastric epithelial cells. Gastroenterology 138: 447-448, 2010.

26. Casas E, Kim J, Bendesky A, Ohno-Machado L, Wolfe CJ and Yang J: Snail2 is an essential mediator of Twist1-induced epithelial mesenchymal transition and metastasis. Cancer Res 71: 245-254, 2011.

27. Yang J, Mani SA, Donaher JL, Ramaswamy S, Itzykson RA, Come C, Savagner P, Gitelman I, Richardson A and Weinberg RA: Twist, a master regulator of morphogenesis, plays an essential role in tumor metastasis. Cell 117: 927-939, 2004.

28. Tang TT and Lasky LA: The forkhead transcription factor FOXO4 induces the down-regulation of hypoxia-inducible factor 1 alpha by a von Hippel-Lindau protein-independent mechanism. J Biol Chem 278: 30125-30135, 2003.

29. Yang H, Zhao R, Yang HY and Lee MH: Constitutively active FOXO4 inhibits Akt activity, regulates p27 Kip1 stability, and suppresses HER2-mediated tumorigenicity. Oncogene 24: 1924-1935, 2005. 